\title{
Pattern of Stress Accumulation Due To a Sudden Movement across a Long Vertical Strike-Slip Fault in a Three-Layered Elastic/ Viscoelastic Model
}

\author{
Bula Mondal ${ }^{1}$, Sanjay Sen $^{2}$ \\ ${ }^{1}$ Assistant Teacher, Joka Bratachari Vidyasram Girls' High School, P.O. Joka, Kolkata-700104, India, Email \\ Id: bulakarmakar79@gmail.com \\ ${ }^{2}$ Professor, Department of Applied Mathematics, University of Calcutta, Calcutta-700009, India, Email Id : \\ dr.sanjaysen@rediff.com
}

\begin{abstract}
The lithosphere-asthenosphere system has been represented by multi-layered model consisting of two parallel layers, the first one is elastic and the second one is viscoelastic, overlying a viscoelastic half-space and they are assumed to be in welded contact. A vertical buried strike-slip fault is taken to be situated in the viscoelastic layer. The fault undergoes a sudden slip under the action of tectonic forces such as mantle convection. Analytical expressions for displacements, stresses and strains are calculated for both layers and half-space by using modified Green's function technique and correspondence principle. Numerical computations have been carried out to find the effect of fault movement in change of surface shear stress. The contour map for the stress pattern in both of the first layer and second layer have been prepared.
\end{abstract}

Keywords: Lithosphere-asthenosphere system, aseismic state, strike-slip fault, mantle-convection, sudden movement, Green's function, correspondence principle, Maxwell type.

\section{Introduction}

Most of the active seismic zones are surrounded by a number of fault system. In these zones it has been observed that during aseismic period, there exist a slow, quasi-static surface deformations which indicates that there was an accumulation of stress and strain in these region. Continuous accumulation of stress near fault may leads to a sudden movement across the fault. So for better understanding of earthquake process which occurs in cyclic order it is necessary to observe the ground deformations near active faults. Such study may help to construct a mathematical model for developing the earthquake prediction problem. In this paper we consider the lithosphere-asthenosphere system as a multi-layered half space (elastic/ viscoelastic). A wide range of model has been developed by many authors like Rybicki [1,2], Mukhopadhyay [3,4], Sen and Debnath [5], Debnath and Sen [6-8], Debnath and Sen [9-11], Mondal and Sen [12], Karmakar and Sen [13] etc. The material of viscoelastic layer and half-space have been taken as Maxwell type with different effective rigidities and viscocities.

\section{Formulation}

We consider a theoretical model of the lithosphere-asthenosphere system consisting of two parallel layers of which the first layer is elastic and the second layer is viscoelastic, overlying on a viscoelastic halfspace. The material of the viscoelastic layer and half-space are of Maxwell type with the different effective rigidity and effective viscosity. The depth of the boundary dividing two layers is $h_{1}$ and the depth of dividing viscoelastic layer and viscoelastic half-space is $h_{2}\left(h_{2}>h_{1}\right)$ from free surface. These two layers and the second layer and half-space are in welded contact. A plane buried vertical strike-slip fault whose length is large compared to its width $l$ is taken to be situated in the viscoelastic layer. The upper and lower edges of the fault are horizontal. The depth of upper edge of the fault below the free surface is $\left(h_{1}+r_{1}\right), r_{1}$ being the depth of the upper edge of the fault from the first surface of separation.

A Cartesian co-ordinate system $\left(y_{1}, y_{2}, y_{3}\right)$ with the plane free surface as the plane $y_{3}=0$ have been considered, $y_{3}$-axis is pointing downwards into the medium and $y_{1}$-axis is taken along the strike of the fault on free surface. The boundary surfaces between the two layers and the viscoelastic layer and viscoelastic halfspaces are given by the planes $y_{3}=h_{1}$ and $y_{3}=h_{2}$ respectively. With this choice of co-ordinate system the elastic layer occupies the region $\left(0 \leq y_{3} \leq h_{1},\left|y_{2}\right|<\infty\right)$, the viscoelastic layer occupies the region $\left(h_{1} \leq y_{3} \leq\right.$ $\left.h_{2},\left|y_{2}\right|<\infty\right)$ and the viscoelastic half-space occupies the region $\left(y_{3} \geq h_{2},\left|y_{2}\right|<\infty\right)$. For convenience of analysis we introduce another set of Cartesian co-ordinate axes $\left(y_{1}^{\prime}, y_{2}^{\prime}, y_{3}^{\prime}\right)$ with the strike of the fault as $y_{1}^{\prime}$ axis and the plane of the fault is given by the plane $y_{2}^{\prime}=0$, so that the fault $F$ is given by $F:\left(y_{2}^{\prime}=0,0 \leq\right.$ $y_{3}^{\prime} \leq l$ ). The relations between two co-ordinate systems is given by

$$
y_{1}=y_{1}^{\prime}, y_{2}=y_{2}^{\prime}, y_{3}=h_{1}+r_{1}+y_{3}^{\prime}
$$


The Figure 1 shows the section of the theoretical model by the plane $y_{1}=0$.

Since we consider a long vertical strike-slip fault then the displacements, stresses and strains are taken to be independent of $y_{1}$ and functions of $y_{2}, y_{3}, t$. Then the components of displacement, stress and strain can be divided into two groups, one associated with strike-slip movement and another associated with dip-slip movement of the fault. Since in this model the strike-slip movement of the fault is considered, then the components of displacement, stress and strain associated with this strike-slip movement are $u_{1},\left(\tau_{12}, \tau_{13}\right)$, $\left(e_{12}, e_{13}\right)$ for elastic layer, $u_{1}^{\prime},\left(\tau_{12}^{\prime}, \tau_{13}^{\prime}\right),\left(e_{12}^{\prime}, e_{13}^{\prime}\right)$ for viscoelastic layer and $u_{1}^{\prime \prime},\left(\tau_{12}^{\prime \prime}, \tau_{13}^{\prime \prime}\right),\left(e_{12}^{\prime \prime}, e_{13}^{\prime \prime}\right)$ for viscoelastic half-space respectively.

\subsection{Constitutive equations}

\section{Stress-strain relations:}

$$
\left.\begin{array}{c}
\tau_{12}=\mu_{1} \frac{\partial u_{1}}{\partial y_{2}} \\
\tau_{13}=\mu_{1} \frac{\partial u_{1}}{\partial y_{3}}
\end{array}\right\}
$$

for elastic layer $\left(0 \leq y_{3} \leq h_{1},\left|y_{2}\right|<\infty\right), t \geq 0$

where $\mu_{1}$ is the rigidity of the elastic layer which is assumed to be constant.

$$
\left.\begin{array}{l}
\left(\frac{1}{\eta_{2}}+\frac{1}{\mu_{2}} \frac{\partial}{\partial t}\right) \tau_{12}^{\prime}=\frac{\partial^{2} u_{1}^{\prime}}{\partial t \partial y_{2}} \\
\left(\frac{1}{\eta_{2}}+\frac{1}{\mu_{2}} \frac{\partial}{\partial t}\right) \tau_{13}^{\prime}=\frac{\partial^{2} u_{1}^{\prime}}{\partial t \partial y_{3}}
\end{array}\right\}
$$

for the viscoelastic layer $\left(h_{1} \leq y_{3} \leq h_{2},-\infty<y_{2}<\infty\right), t \geq 0$.

where $\mu_{2}$ is the effective rigidity and $\eta_{2}$ is the effective viscosity of the viscoelastic layer which are assumed to be constant.

$$
\left.\begin{array}{l}
\left(\frac{1}{\eta_{3}}+\frac{1}{\mu_{3}} \frac{\partial}{\partial t}\right) \tau_{12}^{\prime \prime}=\frac{\partial^{2} u_{1}^{\prime \prime}}{\partial t \partial y_{2}} \\
\left(\frac{1}{\eta_{3}}+\frac{1}{\mu_{3}} \frac{\partial}{\partial t}\right) \tau_{13}^{\prime \prime}=\frac{\partial^{2} u_{1}^{\prime \prime}}{\partial t \partial y_{3}}
\end{array}\right\}
$$

for the viscoelastic half-space $\left(y_{3} \geq h_{2},-\infty<y_{2}<\infty\right), t \geq 0$.

where $\mu_{3}$ is the effective rigidity and $\eta_{3}$ is the effective viscosity of the viscoelastic half-space which are assumed to be constant. The time $t$ being measured form a suitable instant when there is no seismic disturbance.

\section{Stress equation of motion:}

For a slow, aseismic, quasi-static deformation the magnitude of inertial terms are very small compared to the other terms in stress equation of motion and they can be neglected. Hence relevant stresses satisfy the relations

$$
\frac{\partial \tau_{12}}{\partial y_{2}}+\frac{\partial \tau_{13}}{\partial y_{3}}=0
$$

for elastic layer $\left(0 \leq \mathrm{y}_{3} \leq \mathrm{h}_{1},\left|\mathrm{y}_{2}\right|<\infty\right)$

$$
\frac{\partial \tau_{12}^{\prime}}{\partial y_{2}}+\frac{\partial \tau_{13}^{\prime}}{\partial y_{3}}=0
$$

for viscoelastic layer $\left(h_{1} \leq y_{3} \leq h_{2},\left|y_{2}\right|<\infty\right)$

$$
\frac{\partial \tau_{12}^{\prime \prime}}{\partial y_{2}}+\frac{\partial \tau_{13}^{\prime \prime}}{\partial y_{3}}=0
$$

From equation (2)-(7) we get

for viscoelastic half-space $\left(y_{3} \geq h_{2},\left|y_{2}\right|<\infty\right)$.

$$
\begin{aligned}
& \nabla^{2} u_{1}=0 \text { for }\left(0 \leq \mathrm{y}_{3} \leq \mathrm{h}_{1},\left|\mathrm{y}_{2}\right|<\infty\right) \\
& \nabla^{2} u_{1}^{\prime}=0 \text { for }\left(\mathrm{h}_{1} \leq \mathrm{y}_{3} \leq \mathrm{h}_{2},\left|\mathrm{y}_{2}\right|<\infty\right) \\
& \nabla^{2} u_{1}^{\prime \prime}=0 \text { for }\left(\mathrm{y}_{3} \geq \mathrm{h}_{2},\left|\mathrm{y}_{2}\right|<\infty\right)
\end{aligned}
$$




\subsection{Boundary Conditions}

Since the free surface is stress free and the two layers and second layer and half-space are assumed to be in welded contact, then the boundary conditions are

$$
\left.\begin{array}{c}
\tau_{13}=0 \text { at } \mathrm{y}_{3}=0 \\
\tau_{13}=\tau_{13}^{\prime} \text { at } \mathrm{y}_{3}=\mathrm{h}_{1} \\
\mathrm{u}_{1}=\mathrm{u}_{1}^{\prime} \text { at } \mathrm{y}_{3}=\mathrm{h}_{1} \\
\tau_{13}^{\prime}=\tau_{13}^{\prime \prime} \text { at } \mathrm{y}_{3}=\mathrm{h}_{2} \\
\mathrm{u}_{1}^{\prime}=\mathrm{u}_{1}^{\prime \prime} \text { at } \mathrm{y}_{3}=\mathrm{h}_{2} \\
\tau_{13}^{\prime \prime} \rightarrow 0 \text { as } \mathrm{y}_{3} \rightarrow \infty \\
\text { for }\left|\mathrm{y}_{2}\right|<\infty, t \geq 0
\end{array}\right\}
$$

\subsection{Initial Conditions}

We measure the time $\mathrm{t}$ from a suitable instant when the model is in aseismic state and there is no seismic disturbance in it. $\left(u_{1}\right)_{0},\left(u_{1}^{\prime}\right)_{0},\left(u_{1}^{\prime \prime}\right)_{0},\left(\tau_{12}\right)_{0}, \cdots,\left(e_{12}^{\prime \prime}\right)_{0}$ are the values of $u_{1}, u_{1}^{\prime}, u_{1}^{\prime \prime}, \ldots, e_{12}^{\prime \prime}$ at time $t=0$ and they satisfy all the relations stated above.

\subsection{Conditions at Infinity and Initial Conditions}

At a large distance from fault plane there is a shear strain which may changes with time maintained by tectonics forces. Then

$$
\left.\begin{array}{c}
\mathrm{e}_{12} \rightarrow\left(\mathrm{e}_{12}\right)_{000}+\mathrm{g}(\mathrm{t}) \\
\text { for } 0 \leq y_{3} \leq h_{1} \\
\mathrm{e}_{12}^{\prime} \rightarrow\left(\mathrm{e}_{12}^{\prime}\right)_{000}+\mathrm{g}(\mathrm{t}) \\
\text { for } h_{1} \leq y_{3} \leq h_{2} \\
\mathrm{e}_{12}^{\prime \prime} \rightarrow\left(\mathrm{e}_{12}^{\prime \prime}\right)_{0 \infty}+\mathrm{g}(\mathrm{t}) \\
\text { for } y_{3} \geq h_{2} \\
\text { as }\left|\mathrm{y}_{2}\right| \rightarrow \infty, \mathrm{t} \geq 0
\end{array}\right\}
$$

where $\quad\left(\mathrm{e}_{12}\right)_{0 \infty}=\lim _{\left|\mathrm{y}_{2}\right| \rightarrow \infty}\left(\mathrm{e}_{12}\right)_{0} \quad,\left(e_{12}^{\prime}\right)_{0 \infty}=\lim _{\left|y_{2}\right| \rightarrow \infty}\left(e_{12}^{\prime}\right)_{0}, \quad\left(e_{12}^{\prime \prime}\right)_{0 \infty}=\lim _{\left|y_{2}\right| \rightarrow \infty}\left(e_{12}^{\prime \prime}\right)_{0}, \quad$ where

$\left(e_{12}\right)_{0},\left(e_{12}^{\prime}\right)_{0},\left(e_{12}^{\prime \prime}\right)_{0}$ are the values of $e_{12}, e_{12}^{\prime}, e_{12}^{\prime \prime}$ at $\mathrm{t}=0$ and $g(t)$ is a slowly increasing, continuous function of $t$ with $g(0)=0$. Same $g(t)$ is taken for layers and half-space, since they are in welded contact, so that strains are continuous at the boundaries.

\section{Displacements, Stresses And Strains In The Absence of Fault Movement}

To obtain the solution for displacements, stresses and strains in the absence of any fault movement, we take the Laplace transforms of (2)-(12) with respect to time t. This transformation transfers the aforesaid boundary value problem to another boundary value problem in transformed domain which can be solved easily. Then using Laplace inverse transformation and correspondence principle, finally we get the following solutions:

$$
\begin{aligned}
& \text { for first elastic layer }\left(0 \leq \mathrm{y}_{3} \leq \mathrm{h}_{1},\left|\mathrm{y}_{2}\right|<\infty\right) \\
& \left.\begin{array}{c}
u_{1}=\left(u_{1}\right)_{0}+y_{2} g(t) \\
\tau_{12}=\left(\tau_{12}\right)_{0}+\mu_{1} g(t) \\
\tau_{13}=\left(\tau_{13}\right)_{0} \\
e_{12}=\left(e_{12}\right)_{0}+g(t)
\end{array}\right\}
\end{aligned}
$$

for second elastic layer $\left(h_{1} \leq y_{3} \leq h_{2},\left|y_{2}\right|<\infty\right)$

$$
\left.\begin{array}{c}
u_{1}^{\prime}=\left(u_{1}^{\prime}\right)_{0}+y_{2} \mathrm{~g}(\mathrm{t}) \\
\tau_{12}^{\prime}=\left(\tau_{12}^{\prime}\right)_{0} \exp \left(-\frac{\mu_{2} t}{\eta_{2}}\right)+\mu_{2} \int_{0}^{t} g_{1}(\tau) \exp \left\{-\frac{\mu_{2}(t-\tau)}{\eta_{2}}\right\} d \tau \\
\tau_{13}^{\prime}=\left(\tau_{13}^{\prime}\right)_{0} \exp \left(-\frac{\mu_{2} t}{\eta_{2}}\right)
\end{array}\right\}
$$


for half-space $\left(y_{3} \geq h_{2},\left|y_{2}\right|<\infty\right)$

$$
\left.\begin{array}{c}
u_{1}^{\prime \prime}=\left(u_{1}^{\prime \prime}\right)_{0}+y_{2} \mathrm{~g}(\mathrm{t}) \\
\tau_{12}^{\prime \prime}=\left(\tau_{12}^{\prime \prime}\right)_{0} \exp \left(-\frac{\mu_{3} t}{\eta_{3}}\right)+\mu_{3} \int_{0}^{t} g_{1}(\tau) \exp \left\{-\frac{\mu_{3}(t-\tau)}{\eta_{3}}\right\} d \tau \\
\tau_{13}^{\prime \prime}=\left(\tau_{13}^{\prime \prime}\right)_{0} \exp \left(-\frac{\mu_{3} t}{\eta_{3}}\right)
\end{array}\right\}
$$

where $g_{1}(t)=\frac{d}{d t}\{g(t)\}$

From these solution it is observed that there are accumulation of shear strain far away from the fault due to some tectonic reason which implies that there will be an accumulation of shear stress $\tau_{12}^{\prime}$ in the viscoelastic layer. When this accumulated stress exceeds the total cohesive and frictional forces across the fault then there will be a possible movement across it and we consider that this movement is a sudden movement. Then the above solution are no longer valid and required further modifications in order to incorporate the effects of sudden movement across the fault.

\section{Displacements, Stresses And Strains After Restoration of Aseismic State After A Sudden Movement Across The Fault}

It is to be noted that due to the sudden fault movement across the fault $\mathrm{F}$, the accumulated stress will be released at least to some extent and the fault becomes locked again. For a comparatively short period of time during and after sudden fault movement when the seismic disturbances are present then the inertial terms are not small and can not be neglected. So we leave out this short period of time. Now we start with the situation when the model is again in a quasi-static, aseismic state, re-established some time after the sudden movement across the fault, and fix the new time origin $t=0$ at the instant at which the aseismic state is re-established. We shall determine the displacements, stresses and strains during this second phase of aseimic state with this new timeorigin. Since the deformations of the system are slow, aseismic and quasi-static, the inertial forces are small and can be neglected as stated before, so that all the aforesaid constitutive equations and boundary conditions, initial conditions and condition at infinity are also valid for $t \geq 0$ during the aseismic period which is re-established after the sudden movement. In addition to these relations we have one more condition which characterizes the sudden movement across the fault $F\left(y_{2}^{\prime}=0,0 \leq y_{3}^{\prime} \leq l\right)$ after which the fault becomes locked :

$$
\left[u_{1}^{\prime}\right]=U f\left(y_{3}^{\prime}\right) \operatorname{across} F\left(y_{2}^{\prime}=0,0 \leq \mathrm{y}_{3}^{\prime} \leq l\right)(16)
$$

where $\left[u_{1}^{\prime}\right]=\lim _{y_{2}^{\prime} \rightarrow 0^{+}} u_{1}^{\prime}-\lim _{y_{2}^{\prime} \rightarrow 0^{-}} u_{1}^{\prime}$ and $f\left(y_{3}^{\prime}\right)$ is a continuous function of $y_{3}^{\prime}$ and $U$ is constant, independent of $y_{2}^{\prime}$ and $y_{3}^{\prime}$. All the other components $u_{1}, u_{1}^{\prime \prime}, \tau_{12}, \cdots \cdots, e_{13}^{\prime \prime}$ are continuous everywhere in the model.

To solve the above initial and boundary value problem with new time origin $t \geq 0$ for displacements, stresses and strains during aseismic state after commencement of sudden fault movement, we try to find the solutions in the following form:

$$
\left.\begin{array}{rl}
u_{1} & =\left(u_{1}\right)_{1}+\left(u_{1}\right)_{2} \\
\tau_{12} & =\left(\tau_{12}\right)_{1}+\left(\tau_{12}\right)_{2} \\
\tau_{13} & =\left(\tau_{13}\right)_{1}+\left(\tau_{13}\right)_{2} \\
e_{12} & =\left(e_{12}\right)_{1}+\left(e_{12}\right)_{2} \\
& \\
u_{1}^{\prime} & =\left(u_{1}^{\prime}\right)_{1}+\left(u_{1}^{\prime}\right)_{2} \\
\tau_{12}^{\prime} & =\left(\tau_{12}^{\prime}\right)_{1}+\left(\tau_{12}^{\prime}\right)_{2} \\
\tau_{13}^{\prime} & =\left(\tau_{13}^{\prime}\right)_{1}+\left(\tau_{13}^{\prime}\right)_{2} \\
u_{1}^{\prime \prime} & =\left(u_{1}^{\prime \prime}\right)_{1}+\left(u_{1}^{\prime \prime}\right)_{2} \\
\tau_{12}^{\prime \prime} & =\left(\tau_{12}^{\prime \prime}\right)_{1}+\left(\tau_{12}^{\prime \prime}\right)_{2} \\
\tau_{13}^{\prime \prime} & =\left(\tau_{13}^{\prime \prime}\right)_{1}+\left(\tau_{13}^{\prime \prime}\right)_{2}
\end{array}\right\}
$$


where $\left(u_{1}\right)_{1},\left(\tau_{12}\right)_{1}, \cdots \cdots,\left(\tau_{13}^{\prime \prime}\right)_{1}$ satisfy all the stress strain relations (2)-(4), stress equations (5)-(7), boundary conditions (11), initial conditions and conditions at infinity (12). So the solutions for $\left(u_{1}\right)_{1},\left(\tau_{12}\right)_{1}, \ldots,\left(\tau_{13}^{\prime \prime}\right)_{1}$ are given by

$$
\begin{aligned}
& \left(u_{1}\right)_{1}=\left(u_{1}\right)_{p}+y_{2} g(t) \\
& \left(\tau_{12}\right)_{1}=\left(\tau_{12}\right)_{p}+\mu_{1} g(t) \\
& \left(\tau_{13}\right)_{1}=\left(\tau_{13}\right)_{p} \\
& \left(e_{12}\right)_{1}=\left(e_{12}\right)_{p}+g(t) \\
& \begin{array}{c}
\left(u_{1}^{\prime}\right)_{1}=\left(u_{1}^{\prime}\right)_{p}+y_{2} \mathrm{~g}(\mathrm{t}) \\
\left.\left(\tau_{12}^{\prime}\right)_{1}=\left(\tau_{12}^{\prime}\right)_{p} \exp \left(-\frac{\mu_{2} t}{\eta_{2}}\right)+\mu_{2} \int_{0}^{t} g_{1}(\tau) \exp \left\{-\frac{\mu_{2}(t-\tau)}{\eta_{2}}\right\} d \tau\right)
\end{array} \\
& \left(\tau_{13}^{\prime}\right)_{1}=\left(\tau_{13}^{\prime}\right)_{p} \exp \left(-\frac{\mu_{2} t}{\eta_{2}}\right) \\
& \left(u_{1}^{\prime \prime}\right)_{1}=\left(u_{1}^{\prime \prime}\right)_{p}+y_{2} \mathrm{~g}(\mathrm{t}) \\
& \left(\tau_{12}^{\prime \prime}\right)_{1}=\left(\tau_{12}^{\prime \prime}\right)_{p} \exp \left(-\frac{\mu_{3} t}{\eta_{3}}\right)+\mu_{3} \int_{0}^{t} g_{1}(\tau) \exp \left\{-\frac{\mu_{3}(t-\tau)}{\eta_{3}}\right\} d \tau \\
& \left(\tau_{13}^{\prime \prime}\right)_{1}=\left(\tau_{13}^{\prime \prime}\right)_{p} \exp \left(-\frac{\mu_{3} t}{\eta_{3}}\right)
\end{aligned}
$$

where $\left(u_{1}\right)_{p},\left(\tau_{12}\right)_{p}, \cdots \cdots,\left(\tau_{13}^{\prime \prime}\right)_{p}$ are the values of $\left(u_{1}\right)_{1},\left(\tau_{12}\right)_{1}, \cdots \cdots,\left(\tau_{12}^{\prime \prime}\right)_{1}$ respectively at $t=0$ (i.e. new time origin) and $g_{1}(t)=\frac{d}{d t}\{g(t)\}$.

$\left(u_{1}\right)_{2},\left(\tau_{12}\right)_{2}, \cdots \cdots,\left(\tau_{13}^{\prime \prime}\right)_{2}$ satisfy all the above relations (2)-(11) and also satisfy the dislocation condition (16) together with

$$
\left.\begin{array}{c}
\left(e_{12}\right)_{2} \rightarrow 0 \\
\left(e_{12}^{\prime}\right)_{2} \rightarrow 0 \\
\left(e_{12}^{\prime \prime}\right)_{2} \rightarrow 0 \\
\text { as }\left|y_{2}\right| \rightarrow \infty, t \geq 0
\end{array}\right\}
$$

To obtain the solutions for $\left(u_{1}\right)_{2},\left(\tau_{12}\right)_{2}, \cdots \cdots,\left(\tau_{13}^{\prime \prime}\right)_{2}$ for $t \geq 0$ we take Lapace transformation of the aforesaid relations satisfied by them with respect to $t$. The resulting boundary value problem involves with $\left(\bar{u}_{1}\right)_{2},\left(\bar{u}_{1}^{\prime}\right)_{2}, \ldots,\left(\bar{\tau}_{13}^{\prime \prime}\right)_{2}$, which are the Laplace transformation of $\left(u_{1}\right)_{2},\left(\tau_{12}\right)_{2}, \cdots \cdots,\left(\tau_{13}^{\prime \prime}\right)_{2}$ respectively with respect to $t$. The transformed boundary value problem can be solved by using modified Green's function technique developed by Maruyama [14] and Rybicki [1,2] and using correspondence principle as explained in Appendix. Then taking inverse Laplace transformation we obtain the solutions of $\left(u_{1}\right)_{2},\left(\tau_{12}\right)_{2}, \cdots \cdots,\left(\tau_{13}^{\prime \prime}\right)_{2}$. Finally we get the complete solutions from (17) as follows:

$$
\left.\begin{array}{c}
u_{1}\left(y_{2}, y_{3}, t\right)=\left(u_{1}\right)_{p}+y_{2} g(t)+\frac{U}{\pi} \psi_{1}^{\prime}\left(y_{2}, y_{3}, t\right) \\
\tau_{12}\left(y_{2}, y_{3}, t\right)=\left(\tau_{12}\right)_{p}+\mu_{1} g(t)+\frac{\mu_{1} U}{\pi} \psi_{2}^{\prime}\left(y_{2}, y_{3}, t\right) \\
\tau_{13}\left(y_{2}, y_{3}, t\right)=\left(\tau_{13}\right)_{p}+\frac{\mu_{1} U}{\pi} \psi_{3}^{\prime}\left(y_{2}, y_{3}, t\right) \\
e_{12}\left(y_{2}, y_{3}, t\right)=\left(e_{12}\right)_{p}+g(t)+\frac{U}{\pi} \psi_{2}^{\prime}\left(y_{2}, y_{3}, t\right)
\end{array}\right\}
$$

for elastic layer $0 \leq y_{3} \leq h_{1},\left|y_{2}\right|<\infty$ 


$$
\left.\begin{array}{c}
u_{1}^{\prime}\left(y_{2}, y_{3}, t\right)=\left(u_{1}^{\prime}\right)_{p}+y_{2} \mathrm{~g}(\mathrm{t})+\frac{U}{2 \pi} \phi_{1}^{\prime}\left(y_{2}, y_{3}, t\right) \\
\tau_{12}^{\prime}\left(y_{2}, y_{3}, t\right)=\left(\tau_{12}^{\prime}\right)_{p} \exp \left(-\frac{\mu_{2} t}{\eta_{2}}\right)+ \\
\mu_{2} \int_{0}^{t} g_{1}(\tau) \exp \left\{-\frac{\mu_{2}(t-\tau)}{\eta_{2}}\right\} d \tau+\frac{U}{2 \pi} \phi_{2}^{\prime}\left(y_{2}, y_{3}, t\right) \\
\tau_{13}^{\prime}\left(y_{2}, y_{3}, t\right)=\left(\tau_{13}^{\prime}\right)_{p} \exp \left(-\frac{\mu_{2} t}{\eta_{2}}\right)+\frac{U}{2 \pi} \phi_{3}^{\prime}\left(y_{2}, y_{3}, t\right)
\end{array}\right\}
$$

for viscoelastic layer $h_{1} \leq y_{3} \leq h_{2},\left|y_{2}\right|<\infty$

$$
\left.\begin{array}{c}
u_{1}^{\prime \prime}\left(y_{2}, y_{3}, t\right)=\left(u_{1}^{\prime \prime}\right)_{p}+y_{2} \mathrm{~g}(\mathrm{t})-\frac{U}{\mu_{3} \pi} \chi_{1}^{\prime}\left(y_{2}, y_{3}, t\right) \\
\tau_{12}^{\prime \prime}\left(y_{2}, y_{3}, t\right)=\left(\tau_{12}^{\prime \prime}\right)_{p} \exp \left(-\frac{\mu_{3} t}{\eta_{3}}\right)+ \\
\mu_{3} \int_{0}^{t} g_{1}(\tau) \exp \left\{-\frac{\mu_{3}(t-\tau)}{\eta_{3}}\right\} d \tau-\frac{U}{\pi} \chi_{2}^{\prime}\left(y_{2}, y_{3}, t\right) \\
\tau_{13}^{\prime \prime}\left(y_{2}, y_{3}, t\right)=\left(\tau_{13}^{\prime \prime}\right)_{p} \exp \left(-\frac{\mu_{3} t}{\eta_{3}}\right)-\frac{U}{\pi} \chi_{3}^{\prime}\left(y_{2}, y_{3}, t\right)
\end{array}\right\}
$$

for viscoelastic half - space $y_{3} \geq h_{2},\left|y_{2}\right|<\infty$

Where $\psi_{1}^{\prime}\left(y_{2}, y_{3}, t\right), \psi_{2}^{\prime}\left(y_{2}, y_{3}, t\right), \psi_{3}^{\prime}\left(y_{2}, y_{3}, t\right), \phi_{1}^{\prime}\left(y_{2}, y_{3}, t\right), \phi_{2}^{\prime}\left(y_{2}, y_{3}, t\right), \phi_{3}^{\prime}\left(y_{2}, y_{3}, t\right)$ and $\chi_{1}^{\prime}\left(y_{2}, y_{3}, t\right)$, $\chi_{2}^{\prime}\left(y_{2}, y_{3}, t\right), \chi_{3}^{\prime}\left(y_{2}, y_{3}, t\right)$ are given in Appendix.

For locked fault, analytical investigations show that the displacements, stresses and strains will be finite and single valued everywhere in the model including the tip of the fault $F$ if the following sufficient conditions are satisfied by $f\left(y_{3}^{\prime}\right)$

(i) $f\left(y_{3}^{\prime}\right)$ and $f^{\prime}\left(y_{3}^{\prime}\right)$ are both continuous function of $y_{3}^{\prime}$ for $0 \leq y_{3}^{\prime} \leq l$.

(ii) $f(0)=0, f(l)=0$ and $f^{\prime}(0)=f^{\prime}(l)=0$.

(iii) Either $f^{\prime \prime}\left(y_{3}^{\prime}\right)$ is continuous in $0 \leq y_{3}^{\prime} \leq l$ or $f^{\prime \prime}\left(y_{3}^{\prime}\right)$ is continuous in $0 \leq y_{3}^{\prime} \leq l$ except for a finite number of points of finite discontinuity in $0 \leq y_{3}^{\prime} \leq l$ or $f^{\prime \prime}\left(y_{3}^{\prime}\right)$ is continuous in $0<y_{3}^{\prime}<l$ except possibly for a finite number of points of finite discontinuity and for the end points of $(0, l)$, there exist real constant $m, n$ both $<1$ such that $\left(y_{3}^{\prime}\right)^{m} f^{\prime \prime}\left(y_{3}^{\prime}\right) \rightarrow 0$ or to a finite limit as $y_{3}^{\prime} \rightarrow 0+0$ and $\left(l-y_{3}^{\prime}\right)^{n} f^{\prime \prime}\left(y_{3}^{\prime}\right) \rightarrow 0$ or to a finite as limit $y_{3}^{\prime} \rightarrow l-0$.

\section{Numerical Results And Discussion}

To study the surface displacements, surface shear strain accumulation and / or release and the shear stress near the fault tending to cause strike-slip movement of the fault we choose $f\left(y_{3}^{\prime}\right)=\frac{y_{3}^{\prime 2}\left(y_{3}^{\prime}-l\right)^{2}}{\left(\frac{l}{2}\right)^{4}}$, for which displacements, stresses and strains remain finite.

It is assumed that due to some tectonic reason there is a slow but steady accumulation of shear strain at a distance far away from the fault. Keeping this in view we take $g(t)$ to be linearly increasing with time and $g(0)=0$. With this assumption, we take $g(t)=k t$. From major earthquakes it has been observed that the stress release may be of the order of 400 bars. So we assume $k=3.2 \times 10^{-14}$, noting also that the observed rate of strain accumulation in seismically active regions during the aseismic period is of the order of $10^{-6}$ to $10^{-8}$ per year.

For $\mu_{1}, \mu_{2}$ and $\mu_{3}$, we take the values $\mu_{1}=0.63 \times 10^{12}$ dynes $/ \mathrm{cm}^{2}, \mu_{2}=0.75 \times 10^{12}$ dynes $/ \mathrm{cm}^{2}$ and $\mu_{3}=2.42 \times 10^{12}$ dynes $/ \mathrm{cm}^{2}$ and values of effective viscosities $\eta_{2}, \eta_{3}$ for viscoelastic layer and viscoelastic half-space are taken as $\eta_{2}=3.0 \times 10^{21}$ poise, $\eta_{3}=3.5 \times 10^{22}$ poise. (from the books and papers of Bullen [15], Aki [16], Bullen and Bolt [17], Cathles [18], Clift [19], Karato [20]).

For $h_{1}, h_{2}$ the thickness of the layers we take $h_{1}=40 \mathrm{~km} ., h_{2}=300 \mathrm{~km} ., r_{1}$ depth of upper edge of the fault below free surface $=5 \mathrm{~km}$. For $l$ the width of the fault we use $l=10 \mathrm{~km}$. noting that for San Andreas fault in North America, the value of $l$ has been estimated to be in the range $5-15 \mathrm{~km} . \mathrm{U}=40 \mathrm{~cm}$. corresponding to the observed relative displacements on the surface for moderate buried strike-slip fault movement. 
Now we compute the following quantities:

(i) The residual surface shear strain due to fault movement near the fault after one year of the time of restoration of aseismic state.

$$
\begin{aligned}
E_{12} & =\left[e_{12}-\left(e_{12}\right)_{p}-g(t)\right]_{y_{3}=0, t=1 \text { year }} \\
& =\left[\frac{U}{\pi} \psi_{2}^{\prime}\left(y_{2}, y_{3}, t\right)\right]_{y_{3}=0, t=1 \text { year }}
\end{aligned}
$$

(ii) Change of shear stress in first layer due to fault movement

$$
\begin{aligned}
& T_{12}=\left[\tau_{12}-\left(\tau_{12}\right)_{p}-\mu_{1} g(t)\right]_{t=1 \text { year }} \\
& =\left[\frac{\mu_{1} U}{\pi} \psi_{2}^{\prime}\left(y_{2}, y_{3}, t\right)\right]_{y_{3}=0, t=1 \text { year }}
\end{aligned}
$$

(iii) Change of shear stress in second layer due to fault movement

$$
T_{12}^{\prime}=\left[\frac{U}{2 \pi} \phi_{2}^{\prime}\left(y_{2}, y_{3}, t\right)\right]_{t=1 \text { year }}
$$

The Figure 2 shows that the magnitude of residual surface shear strain $E_{12}$ after one year of the time when aseismic state is re-established followed by the fault movement is of the order of $10^{-7}$ which is in conformity with the observed result. It is also shown that the curve of residual surface shear strain is symmetrical about $y_{2}=0$. The magnitude is maximum near fault and tends to zero as we move away from the fault.

The Figures 3(a), 3(b), 3(c) show the change in shear stress $T_{12}$ with depth in the first layer due to the movement of the fault situated in the second layer for different values of $y_{2}$. In Figures 3(a), 3(b) it is observed that there are only accumulation of stress whereas in Figure 3(c) it is observed that there is stress release as well as accumulation. So we conclude that due to fault movement there is only accumulation of stress near the strike of the fault but if we move away from the strike of the fault then there will be both accumulation and release of stress.

The Figures 4(a), 4(b) and 4(c) show the change in shear stress $T_{12}^{\prime}$ with depth $y_{3}$ in the second layer due to movement of the fault. It is found that there are both accumulation and release of stress near the fault in all cases. It is also observed that as we move away from the strike of the fault then the stress accumulation area decreased and release area increased. For large value of $y_{2}$ the stress accumulation zone is marginal. In all the cases as we move along depth then the effect of fault movement on stress tend to zero.

The contour maps of change in shear stress in first and second layer due to sudden movement across the fault $\mathrm{F}$ situated in second layer has been shown in Figure 5 and Figure 6 respectively.

\section{Appendix}

Solution for displacements, stresses and strains after the restoration of aseismic state following a sudden strike-slip movement across the fault:

The displacements, stresses and strains after the restoration of new aseismic state followed by a sudden movement across the fault $F$ have been found in the form given by the equations (17), where the solutions for $\left(u_{1}\right)_{1},\left(\tau_{12}\right)_{1}, \ldots,\left(\tau_{13}^{\prime \prime}\right)_{1}$ are given by (18), (19) and (20). The components $\left(u_{1}\right)_{2},\left(\tau_{12}\right)_{2}, \ldots,\left(\tau_{13}\right)_{2}$ satisfy the relations (2)-(11), together with (16) and (21). To obtain the solutions we take the Laplace transformation of these relations with respect to the time $t$ and we get

$$
\begin{aligned}
& \left(\bar{\tau}_{12}\right)_{2}=\mu_{1} \frac{\partial\left(\bar{u}_{1}\right)_{2}}{\partial y_{2}} \\
& \left.\left(\bar{\tau}_{13}\right)_{2}=\mu_{1} \frac{\partial\left(\bar{u}_{1}\right)_{2}}{\partial y_{3}}\right\} \\
& \text { for } 0 \leq \mathrm{y}_{3} \leq \mathrm{h}_{1},-\infty<\mathrm{y}_{2}<\infty \\
& \left(\bar{\tau}_{12}^{\prime}\right)_{2}=\bar{\mu}_{2} \frac{\partial\left(\bar{u}_{1}^{\prime}\right)_{2}}{\partial y_{2}} \\
& \left.\left(\bar{\tau}_{13}^{\prime}\right)_{2}=\bar{\mu}_{2} \frac{\partial\left(\bar{u}_{1}^{\prime}\right)_{2}}{\partial y_{3}}\right\} \\
& \text { for } \mathrm{h}_{1} \leq \mathrm{y}_{3} \leq \mathrm{h}_{2},-\infty<\mathrm{y}_{2}<\infty \\
& \left(\bar{\tau}_{12}^{\prime \prime}\right)_{2}=\bar{\mu}_{3} \frac{\partial\left(\bar{u}_{1}^{\prime \prime}\right)_{2}}{\partial y_{2}} \\
& \left.\left(\bar{\tau}_{13}^{\prime \prime}\right)_{2}=\bar{\mu}_{3} \frac{\partial\left(\bar{u}_{1}^{\prime \prime}\right)_{2}}{\partial y_{3}}\right\}
\end{aligned}
$$


where $\bar{\mu}_{2}=\frac{p}{\frac{p}{\mu_{2}}+\frac{1}{\eta_{2}}}$ and $\bar{\mu}_{3}=\frac{p}{\frac{p}{\mu_{3}}+\frac{1}{\eta_{3}}}$

$$
\text { for } \mathrm{y}_{3} \geq \mathrm{h}_{2},-\infty<\mathrm{y}_{2}<\infty
$$

$$
\begin{aligned}
& \frac{\partial\left(\bar{\tau}_{12}\right)_{2}}{\partial y_{2}}+\frac{\partial\left(\bar{\tau}_{13}\right)_{2}}{\partial y_{3}}=0 \\
& \text { for } 0 \leq \mathrm{y}_{3} \leq \mathrm{h}_{1},-\infty<\mathrm{y}_{2}<\infty \\
& \frac{\partial\left(\bar{\tau}_{12}^{\prime}\right)_{2}}{\partial y_{2}}+\frac{\partial\left(\bar{\tau}_{13}^{\prime}\right)_{2}}{\partial y_{3}}=0 \\
& \text { for } \mathrm{h}_{1} \leq \mathrm{y}_{3} \leq \mathrm{h}_{2},-\infty<\mathrm{y}_{2}<\infty \\
& \frac{\partial\left(\bar{\tau}_{12}^{\prime \prime}\right)_{2}}{\partial y_{2}}+\frac{\partial\left(\bar{\tau}_{13}^{\prime \prime}\right)_{2}}{\partial y_{3}}=0 \\
& \text { for } \mathrm{y}_{3} \geq \mathrm{h}_{2},-\infty<\mathrm{y}_{2}<\infty \\
& \nabla^{2}\left(\bar{u}_{1}\right)_{2}=0 \\
& \text { for } 0 \leq \mathrm{y}_{3} \leq \mathrm{h}_{1},-\infty<\mathrm{y}_{2}<\infty \\
& \nabla^{2}\left(\bar{u}_{1}^{\prime}\right)_{2}=0 \\
& \text { for } \mathrm{h}_{1} \leq \mathrm{y}_{3} \leq \mathrm{h}_{2},-\infty<\mathrm{y}_{2}<\infty \\
& \nabla^{2}\left(\bar{u}_{1}^{\prime \prime}\right)_{2}=0 \\
& \text { for } \mathrm{y}_{3} \geq \mathrm{h}_{2},-\infty<\mathrm{y}_{2}<\infty \\
& \left(\bar{\tau}_{13}\right)_{2}=0 \text { at } \mathrm{y}_{3}=0 \\
& \left(\bar{\tau}_{13}\right)_{2}=\left(\bar{\tau}_{13}^{\prime}\right)_{2} \text { at } \mathrm{y}_{3}=\mathrm{h}_{1} \\
& \left(\overline{\mathrm{u}}_{1}\right)_{2}=\left(\overline{\mathrm{u}}_{1}^{\prime}\right)_{2} \text { at } \mathrm{y}_{3}=\mathrm{h}_{1} \\
& \left(\bar{\tau}_{13}^{\prime}\right)_{2}=\left(\bar{\tau}_{13}^{\prime \prime}\right)_{2} \text { at } y_{3}=h_{2} \\
& \left(\overline{\mathrm{u}}_{1}^{\prime}\right)_{2}=\left(\overline{\mathrm{u}}_{1}^{\prime \prime}\right)_{2} \text { at } \mathrm{y}_{3}=\mathrm{h}_{2} \\
& \left(\bar{\tau}_{13}^{\prime \prime}\right)_{2} \rightarrow 0 \text { as } y_{3} \rightarrow \infty \\
& \text { for }\left|y_{2}\right|<\infty \\
& \begin{array}{l}
\left(\bar{e}_{12}\right)_{2} \rightarrow 0 \\
\left(\bar{e}^{\prime}\right.
\end{array} \\
& \left(\bar{e}^{\prime}{ }_{12}\right)_{2} \rightarrow 0 \\
& \left(\bar{e}^{\prime \prime}{ }_{12}\right)_{2} \rightarrow 0 \\
& \text { as }\left|y_{2}\right| \rightarrow \infty \text { ) }
\end{aligned}
$$

and

$$
\left[\left(\bar{u}_{1}^{\prime}\right)_{2}\right]=\frac{U}{p} f\left(y_{3}^{\prime}\right) \operatorname{across} F:\left(\mathrm{y}_{2}^{\prime}=0,0 \leq \mathrm{y}_{3}^{\prime} \leq l\right)
$$

where

$$
\left\{\left(\bar{u}_{1}\right)_{2}, \ldots \ldots \ldots,\left(\bar{\tau}_{13}^{\prime \prime}\right)_{2}\right\}=\int_{0}^{\infty}\left\{\left(u_{1}\right)_{2}, \ldots \ldots \ldots,\left(\tau_{13}^{\prime \prime}\right)_{2}\right\} \exp (-p t) d t
$$

and $p$ being the Laplace transform variable.

The boundary value problem (25)-(36) can be solved by using modified form of Green's function technique developed by Maruyama [1966] and Rybicki [1971] with correspondence principle and following them we get

$$
\begin{aligned}
& \left(\bar{u}_{1}\right)_{2}\left(Q_{1}, P\right)=\int_{F}\left[\left(\bar{u}_{1}^{\prime}\right)_{2}(P)\right]\left\{G_{12(1)}^{1}\left(Q_{1}, P\right) d x_{3}-G_{13(1)}^{1}\left(Q_{1}, P\right) d x_{2}\right\} \\
& \left(\bar{u}_{1}^{\prime}\right)_{2}\left(Q_{2}, P\right)=\int_{F}\left[\left(\bar{u}_{1}^{\prime}\right)_{2}(P)\right]\left\{G_{12(2)}^{1}\left(Q_{2}, P\right) d x_{3}-G_{13(2)}^{1}\left(Q_{2}, P\right) d x_{2}\right\} \\
& \left(\bar{u}_{1}^{\prime \prime}\right)_{2}\left(Q_{3}, P\right)=\int_{F}\left[\left(\bar{u}_{1}^{\prime}\right)_{2}(P)\right]\left\{G_{12(3)}^{1}\left(Q_{3}, P\right) d x_{3}-G_{13(3)}^{1}\left(Q_{3}, P\right) d x_{2}\right\}
\end{aligned}
$$

where $Q_{1}\left(y_{1}, y_{2}, y_{3}\right), Q_{2}\left(y_{1}, y_{2}, y_{3}\right), Q_{3}\left(y_{1}, y_{2}, y_{3}\right)$ are the field points in the first layer, second layer and halfspace respectively and $P\left(x_{1}, x_{2}, x_{3}\right)$ is any point on the fault $F$ and $\left[\left(u_{1}^{\prime}\right)_{2}(P)\right]$ is the magnitude of discontinuity of $u_{1}^{\prime}$ across the fault $F$ and 


$$
\left[\left(\bar{u}_{1}^{\prime}\right)_{2}(P)\right]=\frac{U}{p} f\left(x_{3}\right)
$$

Suppose $P\left(\xi_{1}^{\prime}, \xi_{2}^{\prime}, \xi_{3}^{\prime}\right)$ is any point on $F$ with respect to origin $O^{\prime}\left(0,0, h_{1}+r_{1}\right)$ and then a change of co-ordinate from $\left(x_{1}, x_{2}, x_{3}\right)$ to $\left(\xi_{1}^{\prime}, \xi_{2}^{\prime}, \xi_{3}^{\prime}\right)$ is connected by the relations

$$
x_{1}=\xi_{1}^{\prime}, x_{2}=\xi_{2}^{\prime}, x_{3}=\xi_{3}^{\prime}+r_{1}+h_{1}
$$

Then on the fault $F: \xi_{2}^{\prime}=0$, so, $d \xi_{2}^{\prime}=0$ and $d x_{3}=d \xi_{3}^{\prime}, 0 \leq \xi_{3}^{\prime} \leq l$.

Therefore,

Where

$$
\begin{aligned}
& \left(\bar{u}_{1}\right)_{2}\left(Q_{1}, P\right)=\frac{U}{p} \int_{0}^{l} f\left(\xi_{3}^{\prime}\right) G_{12(1)}^{1}\left(Q_{1}, P\right) d \xi_{3}^{\prime} \\
& \left(\bar{u}_{1}^{\prime}\right)_{2}\left(Q_{2}, P\right)=\frac{U}{p} \int_{0}^{l} f\left(\xi_{3}^{\prime}\right) G_{12(2)}^{1}\left(Q_{2}, P\right) d \xi_{3}^{\prime} \\
& \left(\bar{u}_{1}^{\prime \prime}\right)_{2}\left(Q_{3}, P\right)=\frac{U}{p} \int_{0}^{l} f\left(\xi_{3}^{\prime}\right) G_{12(3)}^{1}\left(Q_{3}, P\right) d x_{3}^{\prime}
\end{aligned}
$$

$$
\begin{aligned}
& G_{12(1)}^{1}\left(Q_{1}, P\right)=\int_{0}^{\infty}\left[A_{1}(\lambda) e^{-\lambda y_{3}}+B_{1}(\lambda) e^{\lambda y_{3}}\right] \sin \left[\lambda\left(x_{2}-y_{2}\right)\right] \\
& \left.\begin{array}{rl}
G_{12(2)}^{1}\left(Q_{2}, P\right)= & \int_{0}^{\infty}\left[A_{2}(\lambda) e^{-\lambda y_{3}}+B_{2}(\lambda) e^{\lambda y_{3}}\right] \sin \left[\lambda\left(x_{2}-y_{2}\right)\right] d \lambda \\
& -\frac{1}{2 \pi} \frac{x_{2}-y_{2}}{\left(x_{2}-y_{2}\right)^{2}+\left(x_{3}-y_{3}\right)^{2}}
\end{array}\right\} \\
& G_{12(3)}^{1}\left(Q_{3}, P\right)=\int_{0}^{\infty}\left[A_{3}(\lambda) e^{-\lambda y_{3}}+B_{3}(\lambda) e^{\lambda y_{3}}\right] \sin \left[\lambda\left(x_{2}-y_{2}\right)\right] d \lambda(47) \\
& A_{1}(\lambda)=\frac{\bar{\gamma}_{1}}{\pi \Delta_{2}}\left[\left(\bar{\gamma}_{2}-1\right) e^{\lambda\left(2 h_{1}+x_{3}\right)}-\left(\bar{\gamma}_{2}+1\right) e^{\lambda\left(2 h_{1}+2 h_{2}-x_{3}\right)}\right] \\
& A_{2}(\lambda)=-\frac{1}{2 \pi \Delta_{2}}\left[\begin{array}{c}
\left(\bar{\gamma}_{1}+1\right)\left(\bar{\gamma}_{2}+1\right) e^{\lambda\left(2 h_{1}+2 h_{2}-x_{3}\right)}-\left(\bar{\gamma}_{1}-1\right)\left(\bar{\gamma}_{2}-1\right) e^{\lambda\left(4 h_{1}+x_{3}\right)}+ \\
\left(\bar{\gamma}_{1}-1\right)\left(\bar{\gamma}_{2}+1\right) e^{\lambda\left(4 h_{1}+2 h_{2}-x_{3}\right)}-\left(\bar{\gamma}_{1}+1\right)\left(\bar{\gamma}_{2}-1\right) e^{\lambda\left(2 h_{1}+x_{3}\right)}
\end{array}\right] \\
& B_{2}(\lambda)=\frac{\bar{\gamma}_{2}-1}{2 \pi \Delta_{2}}\left\{\begin{array}{c}
\left(\bar{\gamma}_{1}-1\right)\left[e^{\lambda\left(2 h_{1}-x_{3}\right)}+e^{\lambda x_{3}}\right]+ \\
\left(\bar{\gamma}_{1}+1\right)\left[e^{\lambda\left(2 h_{1}+x_{3}\right)}+e^{\lambda\left(2 h_{1}-x_{3}\right)}\right]
\end{array}\right\} \\
& A_{3}(\lambda)=-\frac{1}{\pi \Delta_{2}}\left\{\begin{array}{c}
\left(\bar{\gamma}_{1}-1\right)\left[e^{\lambda\left(4 h_{1}+2 h_{2}-x_{3}\right)}+e^{\lambda\left(2 h_{2}+x_{3}\right)}\right]+ \\
\left(\bar{\gamma}_{1}+1\right)\left[e^{\lambda\left(2 h_{1}+2 h_{2}+x_{3}\right)}+e^{\lambda\left(2 h_{1}+2 h_{2}-x_{3}\right)}\right]
\end{array}\right\} \\
& B_{3}(\lambda)=0 \\
& \left.\Delta_{2}=\left(\bar{\gamma}_{2}-1\right) e^{2 \lambda h_{1}}\left[\left(\bar{\gamma}_{1}+1\right)+\left(\bar{\gamma}_{1}-1\right) e^{2 \lambda h_{1}}\right]+\right\} \\
& \left.\left(\bar{\gamma}_{2}+1\right) e^{2 \lambda h_{2}}\left[\left(\bar{\gamma}_{1}-1\right)+\left(\bar{\gamma}_{1}+1\right) e^{2 \lambda h_{1}}\right] \quad\right\} \\
& \text { where } \bar{\gamma}_{1}=\frac{\bar{\mu}_{2}}{\mu_{1}}, \bar{\gamma}_{2}=\frac{\bar{\mu}_{3}}{\bar{\mu}_{2}} \\
& A_{2}(\lambda) e^{-\lambda y_{3}}+B_{2}(\lambda) e^{\lambda y_{3}} \\
& =-\frac{1}{2 \pi \Delta_{2}}\left[\begin{array}{c}
\left(\bar{\gamma}_{1}+1\right)\left(\bar{\gamma}_{2}+1\right) e^{\lambda\left(2 h_{1}+2 h_{2}-x_{3}\right)}- \\
\left(\bar{\gamma}_{1}-1\right)\left(\bar{\gamma}_{2}-1\right) e^{\lambda\left(4 h_{1}+x_{3}\right)}+ \\
\left(\bar{\gamma}_{1}-1\right)\left(\bar{\gamma}_{2}+1\right) e^{\lambda\left(4 h_{1}+2 h_{2}-x_{3}\right)}- \\
\left(\bar{\gamma}_{1}+1\right)\left(\bar{\gamma}_{2}-1\right) e^{\lambda\left(2 h_{1}+x_{3}\right)}
\end{array}\right] e^{-\lambda y_{3}}+ \\
& \left.\frac{\bar{\gamma}_{2}-1}{2 \pi \Delta_{2}}\left\{\begin{array}{c}
\left(\bar{\gamma}_{1}-1\right)\left[e^{\lambda\left(4 h_{1}-x_{3}\right)}+e^{\lambda x_{3}}\right]+ \\
\left(\bar{\gamma}_{1}+1\right)\left[e^{\lambda\left(2 h_{1}+x_{3}\right)}+e^{\lambda\left(2 h_{1}-x_{3}\right)}\right]
\end{array}\right\} e^{\lambda y_{3}}\right\}
\end{aligned}
$$

Now first part of (49) 
and second part of (49)

$$
-\frac{1}{2 \pi}\left[\begin{array}{c}
\frac{\left(\bar{\gamma}_{1}+1\right)\left(\bar{\gamma}_{2}+1\right)}{\Delta_{2}} e^{\lambda\left(2 h_{1}+2 h_{2}-x_{3}-y_{3}\right)}- \\
\frac{\left(\bar{\gamma}_{1}-1\right)\left(\bar{\gamma}_{2}-1\right)}{\Delta_{2}} e^{\lambda\left(4 h_{1}+x_{3}-y_{3}\right)}+ \\
\frac{\left(\bar{\gamma}_{1}-1\right)\left(\bar{\gamma}_{2}+1\right)}{\Delta_{2}} e^{\lambda\left(4 h_{1}+2 h_{2}-x_{3}-y_{3}\right)}- \\
\frac{\left(\bar{\gamma}_{1}+1\right)\left(\bar{\gamma}_{2}-1\right)}{\Delta_{2}} e^{\lambda\left(2 h_{1}+x_{3}-y_{3}\right)}
\end{array}\right]
$$

$$
\frac{1}{2 \pi}\left\{\begin{array}{l}
\frac{\left(\bar{\gamma}_{1}-1\right)\left(\bar{\gamma}_{2}-1\right)}{\Delta_{2}}\left[e^{\lambda\left(4 h_{1}-x_{3}+y_{3}\right)}+e^{\lambda\left(x_{3}+y_{3}\right)}\right]+ \\
\frac{\left(\bar{\gamma}_{1}+1\right)\left(\bar{\gamma}_{2}-1\right)}{\Delta_{2}}\left[e^{\lambda\left(2 h_{1}+x_{3}+y_{3}\right)}+e^{\lambda\left(2 h_{1}-x_{3}+y_{3}\right)}\right]
\end{array}\right\}
$$

where $a_{1}=\frac{\left(\bar{\gamma}_{2}-1\right)}{\left(\bar{\gamma}_{2}+1\right)}, c_{1}=\frac{\left(\bar{\gamma}_{1}-1\right)}{\left(\bar{\gamma}_{1}+1\right)}$ and $\bar{\gamma}_{1}=\frac{\bar{\mu}_{2}}{\mu_{1}}, \bar{\gamma}_{2}=\frac{\bar{\mu}_{3}}{\bar{\mu}_{2}}$.

Now

$$
\begin{gathered}
\frac{\left(\bar{\gamma}_{1}+1\right)\left(\bar{\gamma}_{2}+1\right)}{\Delta_{2}}=\frac{e^{-2 \lambda\left(h_{1}+h_{2}\right)}}{M} \\
\frac{\left(\bar{\gamma}_{1}-1\right)\left(\bar{\gamma}_{2}-1\right)}{\Delta_{2}}=\frac{a_{1} c_{1} e^{-2 \lambda\left(h_{1}+h_{2}\right)}}{M} \\
\frac{\left(\bar{\gamma}_{1}+1\right)\left(\bar{\gamma}_{2}-1\right)}{\Delta_{2}}=\frac{a_{1} e^{-2 \lambda\left(h_{1}+h_{2}\right)}}{M} \\
\frac{\left(\bar{\gamma}_{1}-1\right)\left(\bar{\gamma}_{2}+1\right)}{\Delta_{2}}=\frac{c_{1} e^{-2 \lambda\left(h_{1}+h_{2}\right)}}{M}
\end{gathered}
$$

where $M=1+a_{1} e^{-2 \lambda h_{2}}+a_{1} c_{1} e^{-2 \lambda\left(h_{2}-h_{1}\right)}+c_{1} e^{-2 \lambda h_{1}}$ and $|M|<1$ (Mondal and Sen [12]).

Now putting the above values in (49) and using (47) then integrating we get

$$
\begin{aligned}
& \frac{1}{2 \pi}\left[-\frac{d_{1}}{d^{2}+d_{1}^{2}}+\frac{a_{1} c_{1} d_{1}}{\left(d_{2}-2 h_{1}+2 h_{2}\right)^{2}+d_{1}^{2}}-\frac{c_{1} d_{1}}{\left(d-2 h_{1}\right)^{2}+d_{1}^{2}}+\right. \\
& \frac{a_{1} d_{1}}{\left(d_{2}+2 h_{2}\right)^{2}+d_{1}^{2}}+\frac{a_{1} c_{1} d_{1}}{\left(2 h_{2}-2 h_{1}-d_{2}\right)^{2}+d_{1}^{2}}+\frac{a_{1} c_{1} d_{1}}{\left(2 h_{2}+2 h_{1}-d\right)^{2}+d_{1}^{2}}+ \\
& \frac{a_{1} d_{1}}{\left(2 h_{2}-d\right)^{2}+d_{1}^{2}}+\frac{a_{1} d_{1}}{\left(2 h_{2}-d_{2}\right)^{2}+d_{1}^{2}}+\frac{a_{1} d_{1}}{\left(d_{1}+2 h_{2}\right)^{2}+d_{1}^{2}}- \\
& \frac{a_{1}^{2} c_{1} d_{1}}{\left(d_{2}+4 h_{2}-2 h_{1}\right)^{2}+d_{1}^{2}}+\frac{a_{1} c_{1} d_{1}}{\left(d+2 h_{2}-2 h_{1}\right)^{2}+d_{1}^{2}}-\frac{a_{1}^{2} d_{1}}{\left(d_{2}+4 h_{2}\right)^{2}+d_{1}^{2}}- \\
& \frac{a_{1}^{2} c_{1} d_{1}}{\left(4 h_{2}-2 h_{1}-d_{2}\right)^{2}+d_{1}^{2}}-\frac{a_{1}^{2} c_{1} d_{1}}{\left(4 h_{2}+2 h_{1}-d\right)^{2}+d_{1}^{2}}-\frac{a_{1}^{2} d_{1}}{\left(4 h_{2}-d\right)^{2}+d_{1}^{2}}- \\
& G_{12(2)}^{1}=\frac{a_{1}^{2} d_{1}}{\left(4 h_{2}-d_{2}\right)^{2}+d_{1}^{2}}+\frac{a_{1} c_{1} d_{1}}{\left(d+2 h_{2}-2 h_{1}\right)^{2}+d_{1}^{2}}-\frac{a_{1}^{2} c_{1}^{2} d_{1}}{\left(d_{2}+4 h_{2}-4 h_{1}\right)^{2}+d_{1}^{2}}+ \\
& \frac{a_{1} c_{1}^{2} d_{1}}{\left(2 h_{2}-4 h_{1}+d\right)^{2}+d_{1}^{2}}-\frac{a_{1}^{2} c_{1} d_{1}}{\left(4 h_{2}-2 h_{1}+d_{2}\right)^{2}+d_{1}^{2}}-\frac{a_{1}^{2} c_{1}^{2} d_{1}}{\left(4 h_{2}-4 h_{1}-d_{2}\right)^{2}+d_{1}^{2}}- \\
& \frac{a_{1}^{2} c_{1}^{2} d_{1}}{\left(4 h_{2}-d\right)^{2}+d_{1}^{2}}-\frac{a_{1}^{2} c_{1} d_{1}}{\left(4 h_{2}-2 h_{1}-d\right)^{2}+d_{1}^{2}}-\frac{a_{1}^{2} c_{1} d_{1}}{\left(4 h_{2}-2 h_{1}-d_{2}\right)^{2}+d_{1}^{2}}+ \\
& \frac{c_{1} d_{1}}{\left(2 h_{1}+d\right)^{2}+d_{1}^{2}}-\frac{a_{1} c_{1}^{2} d_{1}}{\left(d_{2}+2 h_{2}\right)^{2}+d_{1}^{2}}+\frac{c_{1}^{2} d_{1}}{d^{2}+d_{1}^{2}}- \\
& \frac{a_{1} c_{1} d_{1}}{\left(d_{2}+2 h_{2}+2 h_{1}\right)^{2}+d_{1}^{2}}-\frac{a_{1} c_{1}^{2} d_{1}}{\left(2 h_{2}-d_{2}\right)^{2}+d_{1}^{2}}-\frac{a_{1} c_{1}^{2} d_{1}}{\left(2 h_{2}+4 h_{1}-d\right)^{2}+d_{1}^{2}}- \\
& \left.\frac{a_{1} c_{1} d_{1}}{\left(2 h_{2}+2 h_{1}-d_{2}\right)^{2}+d_{1}^{2}}-\frac{d_{1}}{d_{2}^{2}+d_{1}^{2}}\right]
\end{aligned}
$$

where $d=x_{3}+y_{3}, d_{1}=x_{2}-y_{2}, d_{2}=y_{3}-x_{3}$

In changed co-ordinate system 
Using (43), (50), (51) we get

$$
\left.\begin{array}{c}
d=x_{3}+y_{3}=\xi_{3}^{\prime}+r_{1}+h_{1}+y_{3} \\
d_{1}=x_{2}-y_{2}=\xi_{2}^{\prime}-y_{2}=-y_{2} \\
d_{2}=y_{3}-x_{3}=y_{3}-\xi_{3}^{\prime}-r_{1}-h_{1}
\end{array}\right\}
$$

$$
\left(\bar{u}_{1}^{\prime}\right)_{2}\left(Q_{2}\right)=\frac{U}{2 \pi} \bar{\phi}_{1}^{\prime}\left(y_{2}, y_{3}, p\right)
$$

Similarly we can calculate the terms $G_{12(1)}^{1}, G_{12(3)}^{1}$ and putting these values in (42) and (44) respectively we get

$$
\begin{gathered}
\left(\bar{u}_{1}\right)_{2}\left(Q_{1}\right)=\frac{U}{\pi} \bar{\psi}_{1}^{\prime}\left(y_{2}, y_{3}, p\right)(53) \\
\left(\bar{u}^{\prime \prime}{ }_{1}\right)_{2}\left(Q_{3}\right)=-\frac{U}{\pi \mu_{3}} \bar{\chi}_{1}^{\prime}\left(y_{2}, y_{3}, p\right)(54)
\end{gathered}
$$

where

$$
\bar{\phi}_{1}^{\prime}\left(y_{2}, y_{3}, p\right)=\int_{0}^{l} f\left(\xi_{3}^{\prime}\right)\left[\begin{array}{c}
\frac{1}{p} \frac{y_{2}}{B_{01}}-\frac{a_{1} c_{1} y_{2}}{p}\left\{\frac{1}{B_{02}}+\frac{1}{B_{05}}+\frac{2}{B_{11}}-\frac{1}{B_{24}}-\frac{1}{B_{28}}\right\}+ \\
\frac{c_{1} y_{2}}{p}\left\{\frac{1}{B_{03}}-\frac{1}{B_{21}}\right\}-\frac{a_{1} y_{2}}{p}\left\{\frac{1}{B_{04}}+\frac{1}{B_{07}}+\frac{1}{B_{08}}+\frac{1}{B_{09}}\right\}+ \\
\frac{a_{1}^{2} c_{1} y_{2}}{p}\left\{\frac{2}{B_{10}}+\frac{2}{B_{13}}+\frac{1}{B_{14}}+\frac{1}{B_{20}}\right\}+\frac{a_{1}^{2} y_{2}}{p}\left\{\frac{1}{B_{12}}+\frac{1}{B_{15}}+\frac{1}{B_{16}}\right\}+ \\
\frac{a_{1}^{2} c_{1}^{2} y_{2}}{p}\left\{\frac{2}{B_{17}}+\frac{2}{B_{19}}+\frac{1}{B_{15}}\right\}-\frac{a_{1} c_{1}^{2} y_{2}}{p}\left\{\frac{1}{B_{18}}-\frac{1}{B_{04}}-\frac{1}{B_{08}}-\frac{1}{B_{26}}\right\} \\
\frac{c_{1}^{2} y_{2}}{p} \frac{1}{B_{01}}+\frac{1}{p} \frac{y_{2}}{B_{29}}
\end{array}\right] d \xi_{3}^{\prime}
$$

and

$$
\begin{gathered}
\bar{\psi}_{1}^{\prime}\left(y_{2}, y_{3}, p\right)=\int_{0}^{l} \frac{f\left(\xi_{3}^{\prime}\right)}{p} \frac{\bar{\mu}_{2}}{\bar{\mu}_{2}+\mu_{1}}\left[\begin{array}{c}
y_{2}\left\{\frac{1}{B_{01}}+\frac{1}{B_{29}}\right\}-a_{1} y_{2}\left\{\frac{1}{B_{04}}+\frac{1}{B_{07}}+\frac{1}{B_{08}}+\frac{1}{B_{09}}\right\}+ \\
a_{1}^{2} y_{2}\left\{\frac{1}{B_{12}}+\frac{1}{B_{15}}\right\}-c_{1} y_{2}\left\{\frac{1}{B_{21}}+\frac{1}{B_{32}}\right\}+ \\
a_{1} c_{1} y_{2}\left\{\frac{1}{B_{24}}+\frac{1}{B_{06}}-\frac{1}{B_{11}}-\frac{1}{B_{05}}\right\}+a_{1}^{2} c_{1} y_{2}\left\{\frac{1}{B_{10}}+\frac{1}{B_{20}}\right\}
\end{array}\right] d \xi_{3}^{\prime}(56 \\
\bar{\chi}_{1}^{\prime}\left(y_{2}, y_{3}, p\right)=\int_{0}^{l} \frac{f\left(\xi_{3}^{\prime}\right)}{p} \frac{\bar{\mu}_{2}}{\bar{\mu}_{2}+\bar{\mu}_{3}}\left[\begin{array}{c}
-y_{2}\left\{\frac{1}{B_{01}}+\frac{1}{B_{29}}\right\}+a_{1} y_{2}\left\{\frac{1}{B_{04}}+\frac{1}{B_{09}}\right\}+ \\
c_{1} y_{2}\left\{\frac{1}{B_{31}}-\frac{1}{B_{3}}\right\}+c_{1}^{2} y_{2}\left\{\frac{1}{B_{01}}+\frac{1}{B_{35}}\right\}+ \\
a_{1} c_{1} y_{2}\left\{\frac{2}{B_{11}}+\frac{1}{B_{30}}+\frac{1}{B_{34}}\right\}+a_{1} c_{1}^{2} y_{2}\left\{\frac{1}{B_{04}}+\frac{1}{B_{33}}\right\}
\end{array}\right] d \xi_{3}^{\prime}(57)
\end{gathered}
$$

Taking Laplace inversions of (53), (52), (54), we get

$$
\begin{gathered}
\left(u_{1}\right)_{2}\left(Q_{1}\right)=\frac{U}{\pi} \psi_{1}^{\prime}\left(y_{2}, y_{3}, t\right)(58) \\
\left(u_{1}^{\prime}\right)_{2}\left(Q_{2}\right)=\frac{U}{2 \pi} \phi_{1}^{\prime}\left(y_{2}, y_{3}, t\right)(59) \\
\left(u^{\prime \prime}{ }_{1}\right)_{2}\left(Q_{3}\right)=-\frac{U}{\pi \mu_{3}} \chi_{1}^{\prime}\left(y_{2}, y_{3}, t\right)(60)
\end{gathered}
$$

where $\psi_{1}^{\prime}\left(y_{2}, y_{3}, t\right), \phi_{1}^{\prime}\left(y_{2}, y_{3}, t\right), \chi_{1}^{\prime}\left(y_{2}, y_{3}, t\right)$ are the inverse Laplace transforms of $\bar{\psi}_{1}^{\prime}\left(y_{2}, y_{3}, p\right)$, $\bar{\phi}_{1}^{\prime}\left(y_{2}, y_{3}, p\right), \bar{\chi}_{1}^{\prime}\left(y_{2}, y_{3}, p\right)$ respectively. Now putting the values of $\left(\bar{u}_{1}\right)_{2},\left(\bar{u}_{1}^{\prime}\right)_{2},\left(\bar{u}_{1}^{\prime}\right)_{2}$ from (53), (52), (54) into (25), (26), (27) we get

$$
\begin{aligned}
& \left(\bar{\tau}_{12}\right)_{2}=\frac{\mu_{1} U}{\pi} \bar{\psi}_{2}^{\prime}\left(y_{2}, y_{3}, p\right)(61) \\
& \left(\bar{\tau}_{13}\right)_{2}=\frac{\mu_{1} U}{\pi} \bar{\psi}_{3}^{\prime}\left(y_{2}, y_{3}, p\right)(62) \\
& \left(\bar{\tau}_{12}^{\prime}\right)_{2}=\frac{U}{2 \pi} \bar{\phi}_{2}^{\prime}\left(y_{2}, y_{3}, p\right)(63) \\
& \left(\bar{\tau}_{13}^{\prime}\right)_{2}=\frac{U}{2 \pi} \bar{\phi}_{3}^{\prime}\left(y_{2}, y_{3}, p\right)(64) \\
& \left(\bar{\tau}_{12}^{\prime \prime}\right)_{2}=-\frac{U}{\pi} \bar{\chi}_{2}^{\prime}\left(y_{2}, y_{3}, p\right)(65) \\
& \left(\bar{\tau}_{13}^{\prime \prime}\right)_{2}=-\frac{U}{\pi} \bar{\chi}_{3}^{\prime}\left(y_{2}, y_{3}, p\right)(66)
\end{aligned}
$$


Taking Laplace inversions

$$
\begin{aligned}
& \left(\tau_{12}\right)_{2}=\frac{\mu_{1} U}{\pi} \psi_{2}^{\prime}\left(y_{2}, y_{3}, t\right)(67) \\
& \left(\tau_{13}\right)_{2}=\frac{\mu_{1} U}{\pi} \psi_{3}^{\prime}\left(y_{2}, y_{3}, t\right)(68) \\
& \left(\tau_{12}^{\prime}\right)_{2}=\frac{U}{2 \pi} \phi_{2}^{\prime}\left(y_{2}, y_{3}, t\right)(69) \\
& \left(\tau_{13}^{\prime}\right)_{2}=\frac{U}{2 \pi} \phi_{3}^{\prime}\left(y_{2}, y_{3}, t\right)(70) \\
& \left(\tau_{12}^{\prime \prime}\right)_{2}=-\frac{U}{2 \pi} \chi_{2}^{\prime}\left(y_{2}, y_{3}, t\right)(71) \\
& \left(\tau_{13}^{\prime \prime}\right)_{2}=-\frac{U}{2 \pi} \chi_{3}^{\prime}\left(y_{2}, y_{3}, t\right)(72)
\end{aligned}
$$

where the expressions for $\psi_{2}^{\prime}\left(y_{2}, y_{3}, t\right), \psi_{3}^{\prime}\left(y_{2}, y_{3}, t\right) ; \phi_{2}^{\prime}\left(y_{2}, y_{3}, t\right), \phi_{3}^{\prime}\left(y_{2}, y_{3}, t\right) ; \chi_{2}^{\prime}\left(y_{2}, y_{3}, t\right), \chi_{3}^{\prime}\left(y_{2}, y_{3}, t\right)$ can be obtained from $\bar{\psi}_{2}^{\prime}\left(y_{2}, y_{3}, p\right), \bar{\psi}_{3}^{\prime}\left(y_{2}, y_{3}, p\right) ; \bar{\phi}_{2}^{\prime}\left(y_{2}, y_{3}, p\right), \bar{\phi}_{3}^{\prime}\left(y_{2}, y_{3}, p\right) ; \bar{\chi}_{2}^{\prime}\left(y_{2}, y_{3}, p\right), \bar{\chi}_{3}^{\prime}\left(y_{2}, y_{3}, p\right)$ respectively by taking inverse Laplace transformation.

Where

$$
\left.\begin{array}{c}
B_{01}=\left(\xi_{3}^{\prime}+r_{1}+h_{1}+y_{3}\right)^{2}+y_{2}^{2} \\
B_{02}=\left(2 h_{2}-3 h_{1}+y_{3}-\xi_{3}^{\prime}-r_{1}\right)^{2}+y_{2}^{2} \\
B_{03}=\left(\xi_{3}^{\prime}+r_{1}-h_{1}+y_{3}\right)^{2}+y_{2}^{2} \\
B_{04}=\left(2 h_{2}-h_{1}+y_{3}-\xi_{3}^{\prime}-r_{1}\right)^{2}+y_{2}^{2} \\
B_{05}=\left(2 h_{2}-h_{1}-y_{3}+\xi_{3}^{\prime}+r_{1}\right)^{2}+y_{2}^{2} \\
B_{06}=\left(2 h_{2}+h_{1}-y_{3}-\xi_{3}^{\prime}-r_{1}\right)^{2}+y_{2}^{2} \\
B_{07}=\left(2 h_{2}-h_{1}-y_{3}-\xi_{3}^{\prime}-r_{1}\right)^{2}+y_{2}^{2} \\
B_{08}=\left(2 h_{2}+h_{1}-y_{3}+\xi_{3}^{\prime}+r_{1}\right)^{2}+y_{2}^{2}=B_{25} \\
B_{09}=\left(2 h_{2}+h_{1}+y_{3}+\xi_{3}^{\prime}+r_{1}\right)^{2}+y_{2}^{2} \\
B_{10}=\left(4 h_{2}-3 h_{1}+y_{3}-\xi_{3}^{\prime}-r_{1}\right)^{2}+y_{2}^{2} \\
B_{11}=\left(2 h_{2}-h_{1}+y_{3}+\xi_{3}^{\prime}+r_{1}\right)^{2}+y_{2}^{2} \\
B_{12}=\left(4 h_{2}-h_{1}+y_{3}-\xi_{3}^{\prime}-r_{1}\right)^{2}+y_{2}^{2} \\
B_{13}=\left(4 h_{2}-h_{1}-y_{3}+\xi_{3}^{\prime}+r_{1}\right)^{2}+y_{2}^{2} \\
B_{14}=\left(4 h_{2}+h_{1}-y_{3}-\xi_{3}^{\prime}-r_{1}\right)^{2}+y_{2}^{2} \\
B_{15}=\left(4 h_{2}-h_{1}-y_{3}-\xi_{3}^{\prime}-r_{1}\right)^{2}+y_{2}^{2} \\
B_{16}=\left(4 h_{2}+h_{1}-y_{3}+\xi_{3}^{\prime}+r_{1}\right)^{2}+y_{2}^{2} \\
B_{17}=\left(4 h_{2}-5 h_{1}+y_{3}-\xi_{3}^{\prime}-r_{1}\right)^{2}+y_{2}^{2} \\
B_{18}=\left(2 h_{2}-3 h_{1}+y_{3}+\xi_{3}^{\prime}+r_{1}\right)^{2}+y_{2}^{2} \\
B_{19}=\left(4 h_{2}-3 h_{1}-y_{3}+\xi_{3}^{\prime}+r_{1}\right)^{2}+y_{2}^{2} \\
B_{20}=\left(4 h_{2}-3 h_{1}-y_{3}-\xi_{3}^{\prime}-r_{1}\right)^{2}+y_{2}^{2} \\
B_{21}=B_{31}=\left(3 h_{1}+y_{3}+\xi_{3}^{\prime}+r_{1}\right)^{2}+y_{2}^{2} \\
B_{24}=B_{30}=\left(2 h_{2}+h_{1}+y_{3}-\xi_{3}^{\prime}-r_{1}\right)^{2}+y_{2}^{2} \\
B_{26}=\left(2 h_{2}+3 h_{1}-y_{3}-\xi_{3}^{\prime}-r_{1}\right)^{2}+y_{2}^{2} \\
B_{28}=\left(2 h_{2}+3 h_{1}-y_{3}+\xi_{3}^{\prime}+r_{1}\right)^{2}+y_{2}^{2} \\
B_{29}=\left(h_{1}-y_{3}+\xi_{3}^{\prime}+r_{1}\right)^{2}+y_{2}^{2} \\
B_{33}=\left(2 h_{2}-3 h_{1}+y_{3}+\xi_{3}^{\prime}+r_{1}\right)^{2}+y_{2}^{2} \\
B_{34}=\left(2 h_{2}-3 h_{1}+y_{3}-\xi_{3}^{\prime}-r_{1}\right)^{2}+y_{2}^{2} \\
B_{35}=\left(3 h_{1}-y_{3}-\xi_{3}^{\prime}-r_{1}\right)^{2}+y_{2}^{2}
\end{array}\right\}
$$




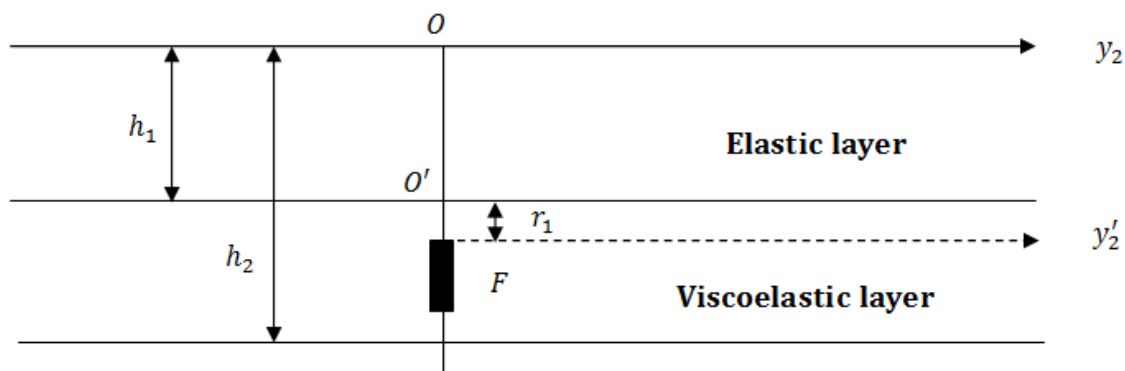

Viscoelastic half - space

$y_{3}, y_{3}^{\prime}$

Figure 1: Section of the model by the plane $y_{1}=0$.

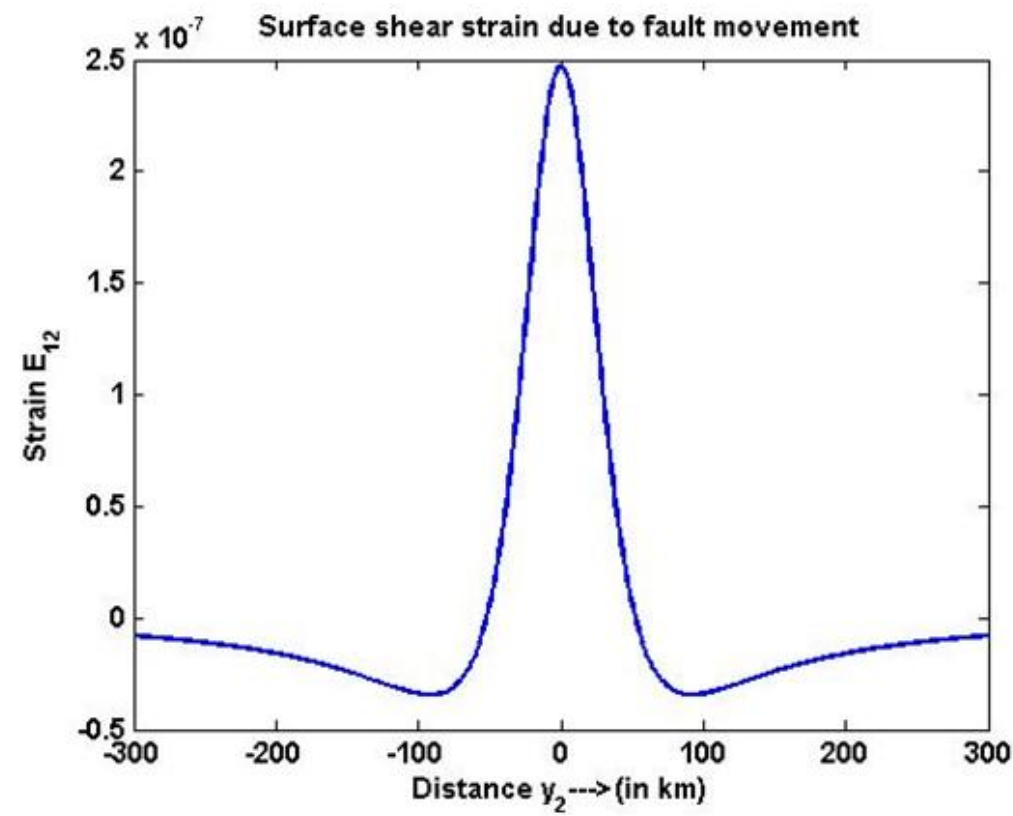

Figure 2: Residual surface shear strain due to fault movement.

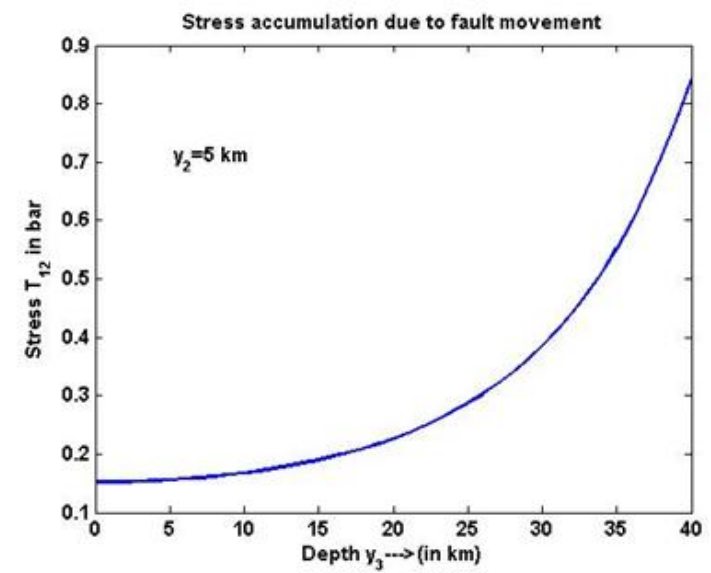

(a)

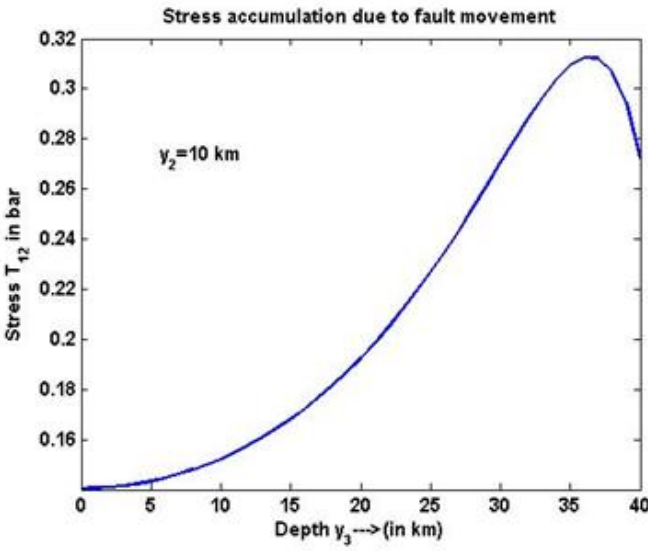

(b) 


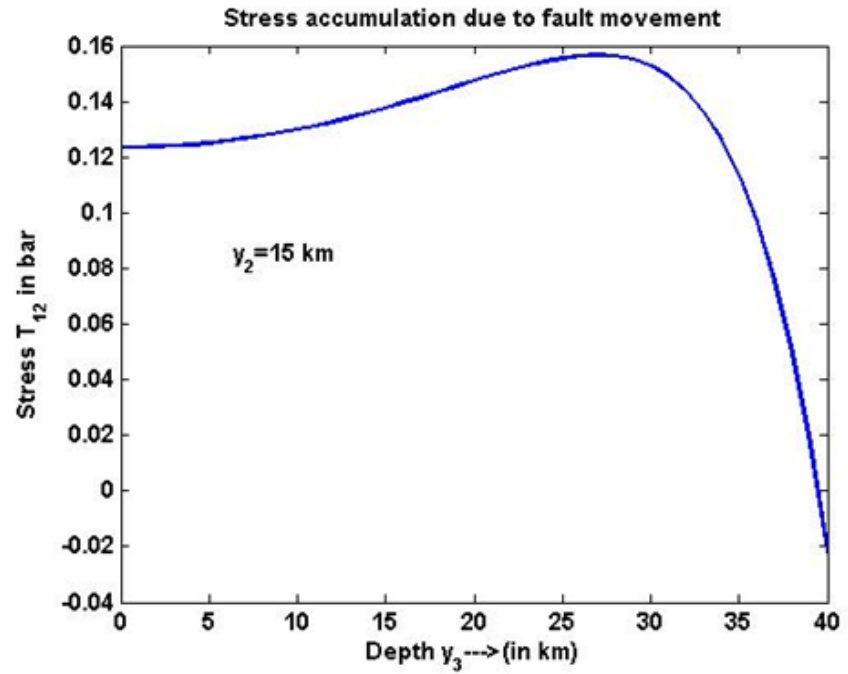

(c)

Figure 3: Surface shear stress in the first layer due to the fault movement. (a) $y_{2}=5 \mathrm{~km}$., (b) $y_{2}=10 \mathrm{~km}$., (c) $y_{2}=15 \mathrm{~km}$.

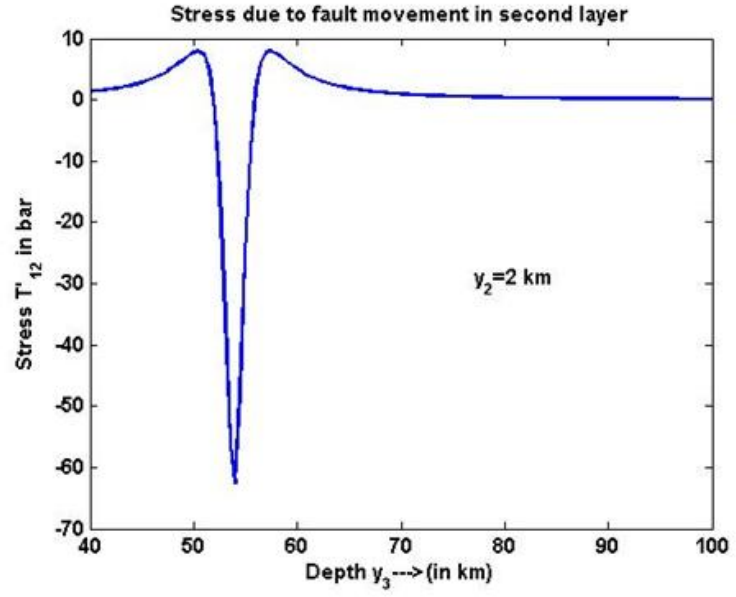

(a)

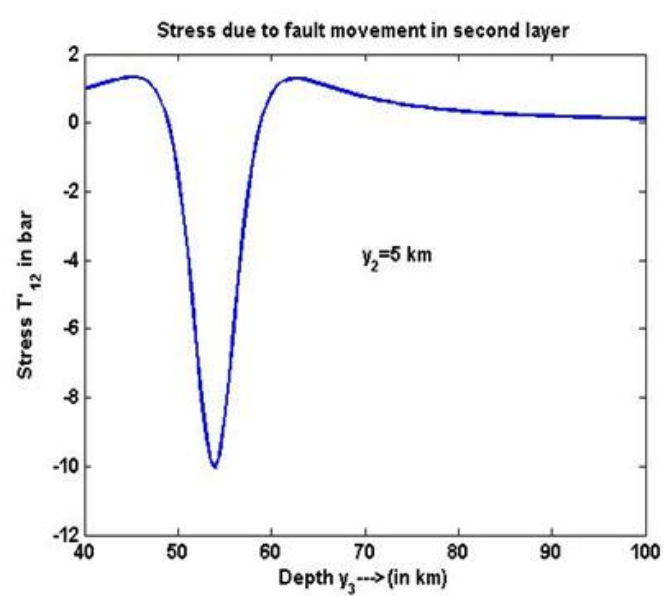

(b)

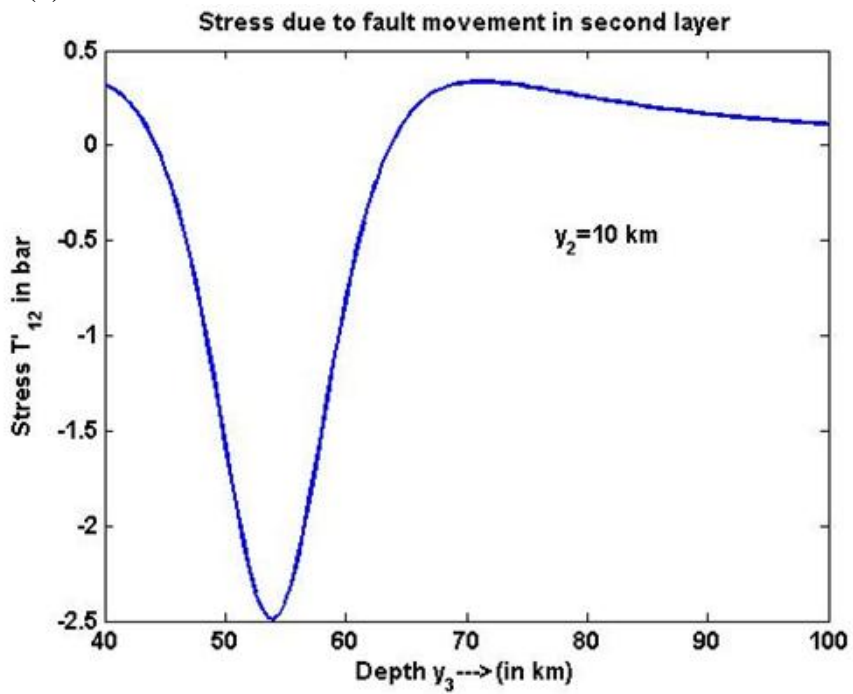

(c)

Figure 4: Surface shear stress due to the fault movement in the second layer.

(a) $y_{2}=2 \mathrm{~km}$., (b) $y_{2}=5 \mathrm{~km}$., (c) $y_{2}=10 \mathrm{~km}$. 


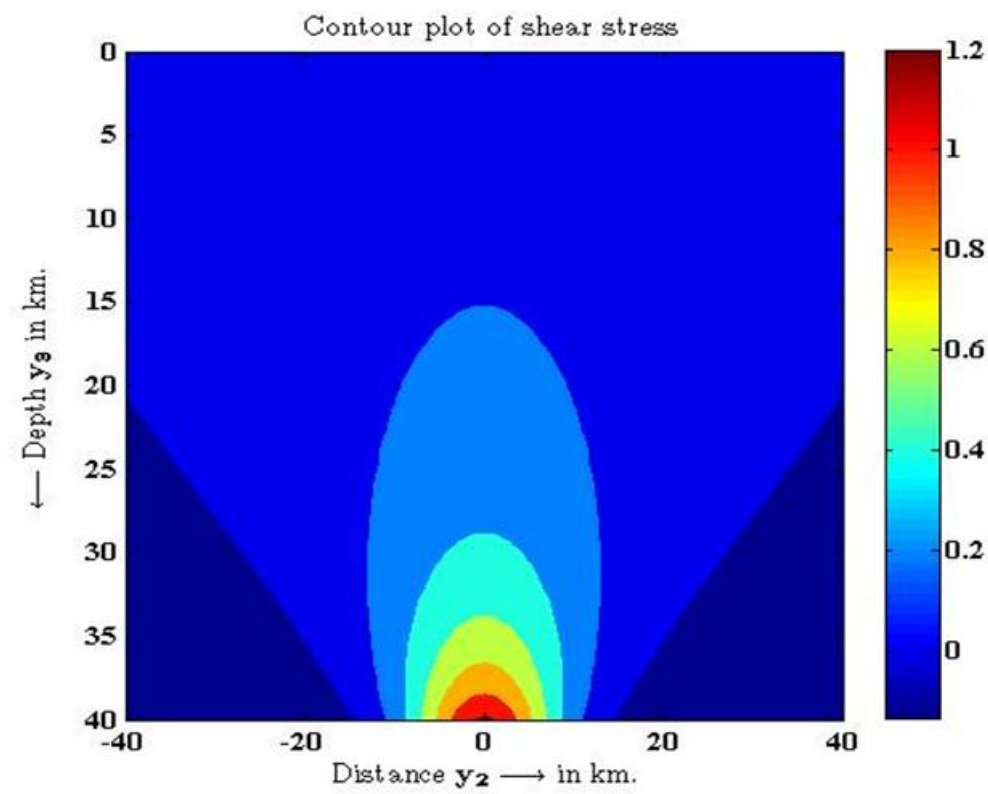

Figure 5: Contour map in the first layer

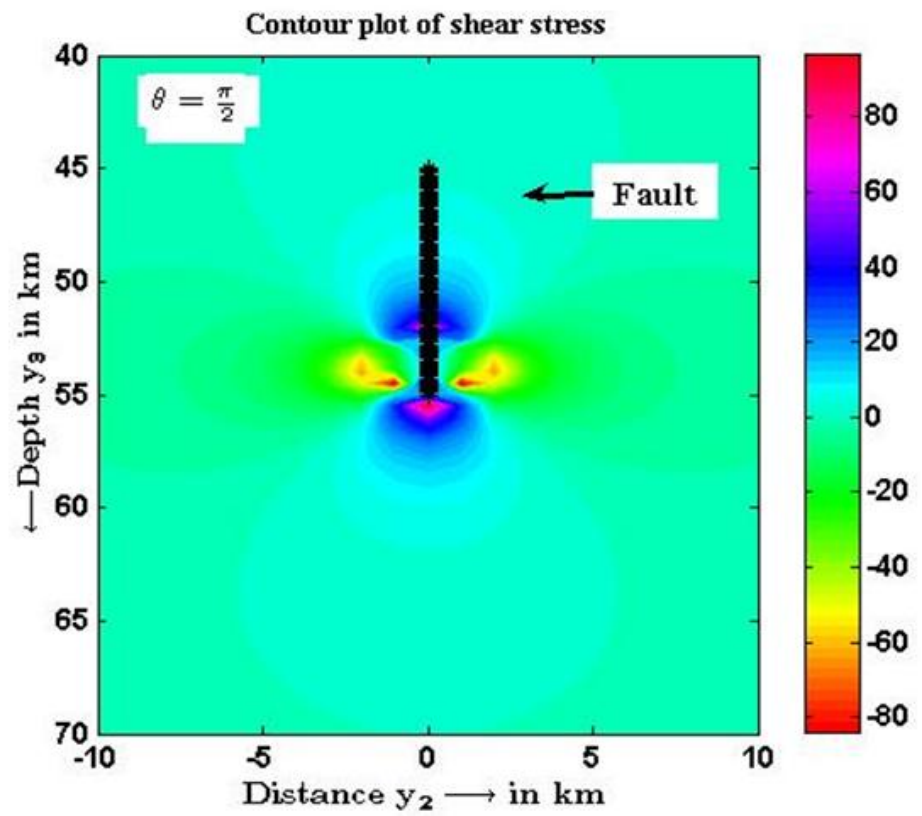

Figure 6: Contour map in the second layer

\section{Acknowledgements}

One of the authors Bula Mondal thanks the Head Mistress of Joka Bratachari Vidyasram Girls' High School for allowing me to pursue the research, and also thanks the Geological Survey of India; Department of Applied Mathematics, University of Calcutta for providing the library facilities.

\section{References}

[1]. K. Rybicki. "The elastic residual field of a very long strike-slip fault in the presence of a discontinuity". Bull. Seis. Soc. Am., 61, 7992, 1971.

[2]. K. Rybicki. "Static deformation of a multilayered half-space by a very long strike-slip fault", Pure and Applied Geophysics, 110, p1955-1966, 1973.

[3]. A. Mukhopadhyay et.al. "On two interacting creeping vertical surface breaking strike-slip fault in the lithosphere,". Bull. Soc. Earthq. Tech., vol. 21, pp. 163-19, 1984, . (with P. Mukherjee).

[4]. A. Mukhopadhyay et al. "On two Aseismically creeping and interacting buried vertical strike-slip faults in the lithosphere". Bull. Soc. Earthquake Tech., vol.23, pp. 91, 1986. 
[5]. S. Sen and S. K. Debnath. "A Creeping vertical strike-slip fault of finite length in a viscoelastic half-space model of the Lithosphere”. International Journal of Computing. Vol-2, Issue-3, p-687-697, 2012.

[6]. S. K. Debnath, S. Sen. "Aseismic ground deformation in a viscoelastic layer overlying a viscoelastic half-space model of the lithosphere-asthenosphere system". Geosciences, Vol-2 No-3 P-60-67, 2013.

[7]. S. K. Debnath, S. Sen. "Two interacting creeping vertical rectangular strike-slip faults in a viscoelastic half-space model of the lithosphere". International Journal of Scientific \& Engineering Research, vol-4, Issue-6, p-1058-1071, 2013.

[8]. S. K. Debnath, S. Sen. "Pattern of stress-strain accumulation due to a long dip-slip fault movement in a viscoelastic layer over a viscoelastic half-space model of the lithosphere-asthenosphere system". International journal of Applied Mechanics and Engineering. Vol-18, No-3. P-653-670, 2013.

[9]. P. Debnath and S. Sen. "Creeping Movement across a Long Strike-Slip Fault in a Half Space of Linear ViscoelasticMaterial Representing the Lithosphere-Asthenosphere System". Frontiers in Science 2014, 4(2): 21-28, 2014.

[10]. P. Debnath, and S. Sen. "A Vertical Creeping Strike Slip Fault in a Viscoelastic Half Space under the Action of Tectonic Forces Varying with Time". IOSR Journal of Mathematics (IOSR-JM) e-ISSN: 2278-5728, p-ISSN: 2319-765X. Volume 11, Issue 3 Ver. I (May - Jun. 2015), PP 105-114, 2015. www.iosrjournals.org.

[11]. P. Debnath, and S. Sen. "A Finite Rectangular Strike Slip Fault in a Linear Viscoelastic Half Space Creeping Under Tectonic Forces". International Journal of Current Research Vol. 7, Issue, 07, pp.18365-18373, July, 2015.

[12]. B. Mondal and S. Sen, "Long Vertical Strike-Slip Fault in a Multi-Layered Elastic Media". Geosciences, 6(2), 2016, 29-40.

[13]. A. Karmakar and S. Sen. "A Sudden Movement across an Inclined Surface Breaking Strike-Slip Fault in an Elastic Layer Overlying a Viscoelastic Layer and a Viscoelastic Half-Space". IOSR Journal of Applied Geology and Geophysics (IOSR-JAGG),Volume 4, Issue 5 Ver. III (Sep. - Oct. 2016), PP 39-58 www.iosrjournals.org.

[14]. T. Maruyama. "On two dimensional dislocation in an infinite and semi-infinite medium", Bull. earthquake res. inst., tokyo univ., 44, part 3, pp. 811-871, 1966.

[15]. K. E. Bullen. “An Introduction to the Theory of Seismology”.( Cambridge Univ. Press, London, 1963).

[16]. K. Aki. "Scaling Law of Seismic Spectrum.", JGR, vol 72, No. 4, 1967.

[17]. K. E. Bullen and B., Bolt “An Introduction to the Theory of Seismology” (Cambridge Univ. Press., London, 1987).

[18]. L. M. Cathles III. “The viscoelasticity of the Earth's mantle ”. (Princeton University Press, Princeton, N.J, 1975).

[19]. P. Clift, J. Lin and U. Barcktiausen "Evidence of low flexural rigidity and low viscosity lower continental crust during continental break-up in the South China Sea”. Marine and Petroleum Geology., 19, 951-970. 2002.

[20]. S. Karato.“ Rheology of the Earth's mantle ”. A historical review Gondwana Research, vol. 18, Issue-1, 2010. 